\title{
sciendo
}

\section{Effects of Plyometric, Strength and Change of Direction Training on High-School Basketball Player's Physical Fitness}

\author{
by \\ Eduardo Sáez de Villarreal ${ }^{1}$, Jose Galán Molina¹, Guillermo de Castro-Maqueda², José \\ V. Gutiérrez-Manzanedo ${ }^{2}$
}

The study aim was to compare the effects of a 7-week plyometric, strength and change of direction (COD) training program on basketball-specific performance measures in high-school players. Forty male players were randomly assigned to one of the four groups: plyometric ( $P G, n=10)$, strength $(S G, n=10), C O D(C O D G, n=10)$, and control group training (CG, $n=10)$. Two training sessions were performed at weekly intervals before basketball training. Performance of the counter movement jump (CMJ), Abalakov jump (ABKJ), $10 \mathrm{~m}$ zig-zag sprint, $20 \mathrm{~m}$ in line sprint (measurements at 10 and $20 \mathrm{~m}$ ), and sit and reach flexibility test (SRFT) was assessed before and after the intervention. A 4 (group) $\times 2$ (time) repeated measures analysis of variances (ANOVA) was conducted for each variable. Bonferroni post-hoc tests were used when the interaction was significant. Significant (all $p<0.05)$ time $x$ group interaction was noted for SRFT, CMJ, ABK, sprint, and zig-zag $10 \mathrm{~m}$, in favor of the experimental groups compared to the control group. However, improvements in physical fitness were similar between the three experimental groups. In conclusion, 7 weeks of specific plyometric, strength and COD training produced similar medium to large improvements in physical fitness of high-school basketball players.

Key words: vertical jump, pubertal, sport conditioning, youth athletes.

\section{Introduction}

Basketball is a globally popular sport in which improved performance depends on training a combination of skills. Although basketball requires good aerobic recovery from high-intensity activity, there is agreement that good basketball performance depends on anaerobic capacity (Canovas-Lopez et al., 2014; Delextrat and Cohen, 2009), hence it is very important for players to follow a good conditioning program. For example, jumping, sprinting and dribbling are of great importance for basketball players and depend on strength, speed, and coordination (Komi and Bosco, 1978).

Three different kinds of training were used in this investigation: plyometric training, strength training, and change of direction (COD) training. The plyometric exercises combined eccentric and concentric muscle actions in what is termed the stretch-shortening cycle (SSC) (Saez de Villarreal et al., 2009). The SSC improves the ability of the muscle-tendon unit to produce maximal force in minimum time (Komi, 2000). The strength training program comprised traditional resistance training techniques, including selfloading exercises and exercises with additional weight (Harrison, 2010). Finally, the COD training program consisted of circuits performed with a basketball that involved rapid, whole-body movements involving changes of velocity and direction (Sanchez-Sanchez et al., 2018).

Plyometric training has been shown as an effective method to improve performance of explosive actions (e.g., jump, sprint, and COD) (Sáez de Villarreal et al., 2015; Slimani et al., 2016). Several authors concluded how the magnitude of

1 - Universidad Pablo de Olavide, Physical Performance \& Sports Research Center, Seville, Spain.

2 - Department of Physical Education, University of Cadiz (Cádiz, Spain). 
adaptive responses to plyometric training could be different depending on participants' characteristics (e.g., training level, sex, and especially maturity status) (Moran et al., 2017a, 2017b). In this regard, recent studies have reported that maturation may play a crucial role in training adaptations (Meylan et al., 2014; Moran et al., 2017b). Thus, previous studies have revealed the importance of trainability associated with natural accelerated maturity of specific athletic skills (e.g., COD, sprint, or jump) (Meylan et al., 2014; Moran et al., 2017a).

A recent meta-analysis regarding the age-related variation and adaptive responses to plyometric training in youth athletes (Moran et al., 2017a) has found that, categorized into three maturity groups, a greater adaptive response was observed in individuals in the PRE-peak height velocity (PHV) (10-12.9 years) group and in individuals in the POST-PHV (16-18 years) group compared to those in the MID-PHV (13-15.9 years) group. However, another previous review has shown that sprint performance gains due to training are associated with the age of participants (Moran et al., 2017c). Therefore, responses to training are age and maturation dependent in the youth (Moran et al., 2017a, 2017b).

Plyometric and strength training programs are the most commonly used method to improve basketball-specific performance indicators such as jump height. It has been shown that plyometric (Andrejic, 2012; Asadi et al., 2017; Khlifa et al., 2010; Maćkała and Fostiak, 2015; Santos and Janeira, 2011; Zribi et al., 2014) and strength (Santos and Janeira, 2012) training programs, performed separately or in combination (Chappell and Limpisvasti, 2008; Santos and Janeira, 2008), enhance vertical and horizontal jump performance in basketball players. A few studies have described the transfer of the training effects from different plyometric or strength training methods to other skills that are nevertheless critical to young basketball players' performance, such as COD (Kilinç, 2008; Maćkała and Fostiak, 2015). It appears that plyometric training can improve ability to COD when not dribbling a basketball (Asadi et al., 2016), but it is not known whether it also improves COD with a basketball. Plyometric training may be an effective method to improve sprint and agility (Asadi et al., 2017; Banda et al., 2019) performance in youth basketball players and recent research has shown that strength training can also have a positive effect on youth basketball players' sprint performance (Gonzalo-Skok et al., 2016; Alemdaroğlu, 2012).

To the authors' knowledge, no study has examined the effects of a short (7 weeks) period of plyometric training, strength training, and COD training with a ball on vertical jump, flexibility, a zig-zag sprint with a ball and a maximal sprint with a ball in high-school basketball players. The purpose of this study was to compare the effects of plyometric, strength, and COD training on basketball-specific performance measures (jump, sprint, COD, and flexibility). We hypothesized that plyometric training would enhance players' vertical jump, sprinting, COD, and flexibility more than strength or COD training. We believed that a good combined training program and commitment from the players would have positive effects.

\section{Methods}

\section{Participants}

Forty male pubertal (U-15) basketball players from two different teams (age: $14.2 \pm 1.3$ years; body height: $1.68 \pm 0.17 \mathrm{~m}$; body mass: 52.5 $\pm 4.2 \mathrm{~kg}$; body fat content: $18.6 \pm 2.2 \%$; playing experience: $4 \pm 1.6$ years) volunteered to participate in the study (Table 1).

Participants included in this study were analyzed by the maturation equation described by Mirwald et al. (2002). Briefly, to estimate participants maturity status, anthropometric measurements were taken and entered into an equation to predict maturity offset, where maturity offset $=-29.769+0.0003007 \cdot$ Leg Length and Sitting Height interaction -0.01177-age and Leg Length interaction +0.01639 age and Sitting Height interaction +0.445 Leg by Height ratio, where $\mathrm{R}=0.96, \mathrm{R} 2=0.915$ and SEE $=0.490$. Based on the peak height velocity (PHV) offset, participants ranged from -0.4 to +0.4 years.

All players competed in a national league, playing one match a week and training twice a week. Players were excluded from the investigation if they met any of the following criteria: a) injured less three than months prior to the study; b) failure to recover or complete rehabilitation of a previous injury; c) suffering from a condition that would prevent them from 
participating in the technical and tactical basketball training, and/or the experimental training programs; d) missed two or more experimental training sessions, or two or more technical and tactical basketball training sessions. No participant was excluded from the study after recruitment. All participants were in good health and able to participate in the training interventions. Before participating in this project, which was approved by the Institutional Ethics Review Committee of the University, all participants were fully informed about the protocol and their parents or guardians provided written consent to their participation in accordance with current national and international laws and regulations governing the use of human participants in research (Declaration of Helsinki II).

\section{Design and Procedures}

We examined how four different 7 week training interventions affected a number of basketball performance variables: vertical jumping ability, hamstring and lumbar extensibility, and sprinting with a ball. The study was conducted during 7 weeks (14-session) of the basketball season with high-school players. Participating players were randomly assigned to one of the four training groups in a counterbalanced manner. All participants were tested before and after the 7 week training period to determine the effects of the 3 training interventions. The tests performed were a counter movement jump (CMJ), Abalakov jump (ABKJ), sit and reach flexibility test (SRFT), $10 \mathrm{~m}$ zig-zag sprint with the ball, and $20 \mathrm{~m}$ sprint with the ball. After the baseline assessment all participants were assigned to one of the four following groups: plyometric training (PG, $n=10$ ); strength training (SG, $n=10$ ); COD training with the ball (CODG, $n$ $=10)$; and a control group (CG, $n=10)$. All training sessions were supervised by a physical and athletic performance specialist, and participants were instructed in the proper execution of all exercises. All players had experience with these training approaches and were familiarized with the exercise technique. Participants were also instructed to avoid any strenuous physical activity not related to the training intervention and to maintain their usual diet (they were not allowed to drink caffeinebased beverages) for the duration of the study.
All participants were familiarised with the test procedures one week before the baseline assessment. In addition, several warm-up sets were recorded before the actual maximal and explosive tests during each testing session to ensure stability of each measure. Both the baseline and post-training assessments were completed in a single session that took place between 17:00 and 21:00. The baseline assessment was carried out one week before the experimental training programs started and the post-training assessment was performed one week after they had finished. The tests were completed in the following order: $\mathrm{CMJ}$, $\mathrm{ABKJ}, 10 \mathrm{~m}$ zig-zag sprint with the ball, $20 \mathrm{~m}$ sprint with the ball, and SRFT. Before testing all participants completed a warmup consisting of $10 \mathrm{~min}$ of sub-maximal running and a basketball-specific warm-up that involved vertical jumps, sprints, and joint mobility. Ten minute rest intervals between tests were given to limit the effects of fatigue on subsequent tests. All tests were conducted indoors.

\section{Counter Movement Vertical Jump and Abalakov Jump}

The CMJ consists of a jump starting from an upright position, with hands on hips and with counter-movement. The hands are placed on the hips at the start of the test and remain there throughout. The athlete squats until the knees are bent at 90 degrees, then jumps vertically as high as possible, landing on both feet at the same time. In the $\mathrm{ABKJ}$ the athlete squats until the knees are bent at 90 degrees while swinging the arms back behind the body. Then the arms are immediately swung forwards and the athlete jumps as high as possible, landing on both feet at the same time. Both jumps were used to assess explosive strength of the lower limbs. The tests were performed using an optical measurement system (Optojump; Microgate, Milan, Italy) that quantified flight and contact times. Each participant completed 3 trials with $5 \mathrm{~s}$ of rest between trials for each kind of the jump. Three trials were completed, and the best performance was used for the subsequent statistical analysis (Sáez de Villarreal et al., 2008). Participants were instructed to land in an uptight position and to bend the knees after landing.

\section{$10 \mathrm{~m}$ Zig-zag Sprint Test}

Participants sprinted $10 \mathrm{~m}$ with a change of direction. They started from behind the baseline with their left foot forward when they 
were ready and dribbled with their left hand when moving to the left and their right hand when moving to the right. The course was defined by five cones set in the center of the testing area $1.5 \mathrm{~m}$ apart to each other and $1.5 \mathrm{~m}$ from the centerline (Figure 1). Photocells (Microgate, Milan, Italy) were positioned at the beginning and at the end to measure the time taken to complete the course. Two trials were completed and the best was used for further statistical analyses. Two minutes of rest were permitted between trials.

\section{$20 \mathrm{~m}$ Sprint Test}

A $20 \mathrm{~m}$ sprint test was selected because it is a common test used in the evaluation of basketball players' sprinting ability. After the completion of a specific warm-up (i.e. 3-5 submaximal running in the $20 \mathrm{~m}$ line) all participants performed two maximal $20 \mathrm{~m}$ sprints, each separated by two min of rest. Participants initiated the sprint from a standardized starting position that was $0.5 \mathrm{~m}$ behind the start line. Photocells (Microgate, Milan, Italy) were positioned at the beginning, at the $10^{\text {th }}$ and the $20^{\text {th }}$ $\mathrm{m}$, to measure the time taken for the first and second halves of the course and the total time. Two trials were completed and the best result was used for further analyses.

\section{Sit and Reach Flexibility Test}

This test was used to assess lumbar and hamstring flexibility. The participant sat on the floor with legs together, knees extended and the soles of the feet placed against the edge of a box. The thumbs were clasped so that hands were together, palms facing downwards. The participant then extended his arms as far forwards as possible. A sit and reach box was used to measure the distance reached (ACCUFLEX I Flexibility Tester, height: $32 \mathrm{~cm}$; PSYMTEC, Madrid, Spain). Two trials were completed, with a pause of $30 \mathrm{~s}$ between trials and the best result was used for analyses.

\section{Training program}

The three experimental groups followed the appropriate experimental training protocol twice a week (Monday and Wednesday) during 7 weeks of the intervention (14 sessions), before basketball-specific training. The CG only performed standard basketball training. All 40 players completed all training sessions using appropriate boots and clothes for basketball. All sessions lasted $90 \mathrm{~min}$ and consisted of the following components: $10 \mathrm{~min}$ of a standard warm-up, $20 \mathrm{~min}$ of experimental training (plyometric training, strength training or COD training with the ball; experimental groups only), $55 \mathrm{~min}$ of standard basketball training, and $5 \mathrm{~min}$ of cool-down, including stretching exercises. In the experimental training protocols the rest interval between each set was $1 \mathrm{~min}$. The three experimental training programs are outlined in Tables 2, 3, and 4. The plyometric training program was based on the guidelines drawn up by Radcliffe and Farentinos (1999). All training sessions for all groups were fully supervised to ensure that players used the correct technique for each exercise. All participants were carefully instructed on how to perform the experimental exercises. They observed a practical demonstration and performed familiarisation trials. No acute injuries occurred during the training sessions.

\section{Statistical analysis}

The values are expressed as mean \pm standard deviation (SD). Test-retest absolute reliability was assessed using the coefficient of variation $(\mathrm{CV})$, whereas relative reliability was calculated using the intraclass correlation coefficient (ICC) with a 95\% confidence interval $(\mathrm{CI})$, using the one-way random effects model. Homogeneity of variance across groups was verified using the Levene's test, whereas the normality of distribution of the data was examined with the Kolmogorov-Smirnov test. A 4 (group) $\times 2$ (time) repeated measures analysis of variances (ANOVA) was calculated for each variable. Bonferroni post-hoc tests were used when the interaction was significant. Effect sizes (ESs) were calculated with Hedges and Olkin's g (Hedges and Olkin, 1985), using the following formula: $\mathrm{g}=\left(\mathrm{M}_{\text {post }}-\mathrm{M}_{\text {pre }}\right) / \mathrm{SD}_{\text {pooled, }}$ where $\mathrm{M}_{\text {post }}$ is the post-test mean, $\mathrm{M}_{\text {pre }}$ is the pre-test mean, and $\mathrm{SD}_{\text {pooled }}$ is the pooled SD of the measurements. The magnitude of the effect size statistics was considered trivial $<0.20$; small, $0.20-0.50$; moderate, $0.5-0.80$; large, $0.8-1.30$; very large $>1.30$ (Ramírez-Campillo et al., 2014). The ES aws reported in conjunction with the $95 \%$ confidence interval (CI) for all analyzed measures. The level of significance was set at $\mathrm{p} \leq .05$. All statistical analyses were performed with the statistical software package (SPSS 20.0 version, Chicago, Illinois, USA). 


\section{Results}

Analyses of variance (ANOVAs) revealed that at baseline, there were no differences between-groups in any of the strength, flexibility, agility, anthropometric and performance variables tested. The results are outlined in Table 5.

Height in the Counter Movement Jump (CMJ)

After 7 weeks of training (post-test), significant improvements were found in the PG $(4.44 \mathrm{~cm} ; 16.87 \% ; p=0.02)$, SG $(3.16 \mathrm{~cm} ; 11.39 \% ; p$ $=0.004)$, and CG $(0.93 \mathrm{~cm} ; 3.31 \% ; p=0.013)$ in the $\mathrm{CMJ}$ test. Post hoc analyses revealed no betweengroup differences in CMJ height. The coefficient of variation $(\mathrm{CV})$ for test-retest reliability was $2.1 \%$ and the intraclass correlation coefficient (ICC) was 0.95 (95\% CI: 0.92-0.97).

Height in THE Abalakov Jump (ABKJ)

After the 7 week intervention, significant improvements were observed in the PG $(3.96 \mathrm{~cm} ; 13.45 \% ; p=0.009)$ and SG $(2.42 \mathrm{~cm}$; $7.8 \% ; p=0.019)$ in the ABK test, although post hoc analyses showed no between-group differences in ABK height. The coefficient of variation $(\mathrm{CV})$ for test-retest reliability was $2.3 \%$ and the intraclass correlation coefficient (ICC) was 0.92 (95\% CI: 0.90-0.94).

$10 \mathrm{~m}$ Zig-zag Sprint Test

Significant improvements were also found in the CODG $(0.62 \mathrm{~s} ; 9.02 \% ; p=0.012)$ in the $10 \mathrm{~m}$ zig-zag sprint test. Post hoc analyses revealed between-group differences $(p=0.001)$ in times for the $10 \mathrm{~m}$ zig-zag sprint test. The CG was significantly slower $(-0.04 \mathrm{~s}, 0.63 \%$, ES $=0.07)$ than the PG $(-0.47 \mathrm{~s} ; 6.79 \% ; p=0.015)$ and CODG $(-0.62$ s, $9.02 \% ; p=0.001)$. The coefficient of variation (CV) for test-retest reliability was $2.6 \%$ and the intraclass correlation coefficient (ICC) was 0.86 (95\% CI: 0.84-0.88).

$20 \mathrm{~m}$ in line Sprint Test

Following 7 week training, significant improvements were found in the SG $(0.08 \mathrm{~s}$; $4.78 \% ; p=0.015)$ and CODG $(0.20 ; 8.49 \% ; p=$ $0.005)$ in the $20 \mathrm{~m}$ in line sprint test. There were between-group differences $(p=0.004)$ in times for the $20 \mathrm{~m}$ sprint. In the first half of the sprint $(0-10$ $\mathrm{m})$ the CG was significantly slower $(-0.04 \mathrm{~s}, 1.33 \%)$ than the SG $(-0.11 \mathrm{~s}, 4.78 \% ; p=0.008)$ and CODG ($0.20 \mathrm{~s}, 8.49 \% ; p=0.011)$. The coefficient of variation $(\mathrm{CV})$ for test-retest reliability was $2.5 \%$ and the intraclass correlation coefficient (ICC) was 0.88 (95\% CI: 0.86-0.90).

Sit and Reach Flexibility Test (SRFT)

All the groups i.e., PG, SG, CODG, and CG showed a significant improvement in the SRFT $(3.64 \mathrm{~cm}, 412.6 \%$, ES $=2.04 ; 2.94 \mathrm{~cm}, 425 \%$, $\mathrm{ES}=1.4 ; 2.35 \mathrm{~cm}, 201.2 \%$, ES $=0.96$, and $1.27 \mathrm{~cm}$, $101.58 \%$, ES $=1.83$, respectively). Post hoc analyses revealed between-group differences ( $p=$ 0.036) in SRFT performance. Post hoc tests confirmed that the PG and SG achieved a greater distance $(3.64 \mathrm{~cm}, 412.6 \% ; 2.94 \mathrm{~cm}, 425 \%$, respectively) than the CODG $(2.35 \mathrm{~cm}, 201.2 \% ; p=$ $0.025)$. The coefficient of variation $(\mathrm{CV})$ for testretest reliability was $2.5 \%$ and the intraclass correlation coefficient (ICC) was 0.88 (95\% CI: 0.86-0.90).

\begin{tabular}{|c|c|c|c|c|}
\hline \multicolumn{5}{|c|}{$\begin{array}{l}\text { Descriptive data of the sample by groups } \\
\text { Gable } 1 \\
\text { group; CG: control group; PHV: peak height velocity; Y: years. }\end{array}$} \\
\hline Group & Sample size & Age (y) & $\begin{array}{l}\text { Playing experience } \\
\text { (y) }\end{array}$ & PHV offset (y) \\
\hline PG & 10 & $13.57 \pm 1.39$ & $4.85 \pm 1.86$ & $-0.4 \pm 0.3$ \\
\hline SG & 10 & $14.22 \pm 1.56$ & $4.16 \pm 1.54$ & $-0.2 \pm 0.3$ \\
\hline CODG & 10 & $14.28 \pm 1.60$ & $3.85 \pm 1.34$ & $-0.4 \pm 0.4$ \\
\hline CG & 10 & $14.66 \pm 0.86$ & $3.44 \pm 1.50$ & $-0.2 \pm 0.3$ \\
\hline \multicolumn{5}{|c|}{ Values are reported as mean \pm standard deviation. } \\
\hline
\end{tabular}


Table 2

Plyometric training program

\begin{tabular}{|c|c|c|c|}
\hline \multicolumn{4}{|c|}{ Sets $\mathrm{x}$ Time (s) } \\
\hline Weeks 1 and 2 & Weeks 3 and 4 & Weeks 5 and 6 & Week 7 \\
\hline $2 \times 10$ & $2 \times 10$ & $3 \times 10$ & $2 \times 10$ \\
\hline Pogo & Double-leg butt kick & Single-leg stride jump & Scissors jump \\
\hline Box jump (SR) & Scissors jump & Stride jump crossover & Single-leg speed hop \\
\hline Rocket jump & Alternate leg bound & Quick leap & (right and left) \\
\hline Prancing & Single-leg butt kick & Single-leg speed hop & Quick leap \\
\hline Double-leg speed & (right and left) & (right and left) & Depth jump \\
\hline hop & Single-leg hop & Depth jump & Box jump (MR x 4) \\
\hline Side hop & progression (right and & & \\
\hline Side hop sprint & left) & & \\
\hline
\end{tabular}

SR: single response; MR: multiple response; S: seconds

Table 3

Strength training program

\begin{tabular}{|c|c|c|c|c|}
\hline \multicolumn{5}{|c|}{ Sets $x$ Repetitions } \\
\hline Week 1 & Week 2 & Weeks 3 and 4 & Weeks 5 and 6 & Week 7 \\
\hline $2 \times 8$ & $3 \times 10$ & $3 \times 12$ & $3 \times 15$ & $3 \times 12$ \\
\hline Full squat & Full squat & $\begin{array}{l}\text { Full squat } \\
\text { (with } 3 \mathrm{~kg} \mathrm{MB} \text { ) }\end{array}$ & $\begin{array}{l}\text { Full squat } \\
\text { (with } 5 \mathrm{~kg} \mathrm{MB} \text { ) }\end{array}$ & $\begin{array}{l}\text { Full squat } \\
\text { (with } 5 \mathrm{~kg} \mathrm{MB} \text { ) }\end{array}$ \\
\hline Rise to bench* & Rise to bench* & Rise to bench* & Rise to bench* & Rise to bench* \\
\hline Stride ${ }^{*}$ & Stride* & Stride ${ }^{*}$ & Stride & Stride ${ }^{*}$ \\
\hline Calf muscle & Calf muscle & Calf muscle & Calf muscle & Calf muscle \\
\hline
\end{tabular}

*With each leg. It is performed consecutively. MB: medicine ball; kg: kilograms.

Table 4

Change of direction training program with the ball

\begin{tabular}{|c|c|c|c|c|}
\hline \multirow[b]{2}{*}{ Exercises } & \multicolumn{4}{|c|}{ Sets x Distance (m) } \\
\hline & $\begin{array}{l}\text { Weeks } \\
1 \text { and } 2\end{array}$ & $\begin{array}{l}\text { Weeks } \\
3 \text { and } 4\end{array}$ & $\begin{array}{l}\text { Weeks } \\
5 \text { and } 6\end{array}$ & $\begin{array}{c}\text { Week } \\
7\end{array}$ \\
\hline $\begin{array}{l}\text { Zig-zag dribbling with cones in a straight } \\
\text { line }^{* *}\end{array}$ & $8 \times 10$ & $10 \times 10$ & $12 \times 10$ & $10 \times 10$ \\
\hline Dribbling in a straight line $e^{*}$ & $8 \times 10$ & $10 \times 10$ & $12 \times 10$ & $10 \times 10$ \\
\hline $\begin{array}{l}\text { Changing direction } 180^{\circ} \text { (5-m and 5-m } \\
\text { return)** }\end{array}$ & $8 \times 10$ & $10 \times 10$ & $12 \times 10$ & $10 \times 10$ \\
\hline
\end{tabular}

${ }^{*}$ Alternate dribbling (right hand and left hand). A dribble with each hand.

** Half of the sets performed with the right hand and the other half with the left hand.

M: meters 
Table 5

$C M J(\mathrm{~cm}), A B K J(\mathrm{~cm}), 10-m$ zig-zag test (s), 20-m sprint test (s) and SRFT (cm) performance of the experimental groups before and after 7 weeks of training

\begin{tabular}{|c|c|c|c|c|c|c|c|c|}
\hline & \multicolumn{4}{|c|}{$\begin{array}{c}\text { PG } \\
(n=10)\end{array}$} & \multicolumn{4}{|c|}{$\begin{array}{c}\text { SG } \\
(n=10)\end{array}$} \\
\hline & Pre & Post & $\begin{array}{c}\% \\
\text { change }\end{array}$ & ES & Pre & Post & $\begin{array}{c}\% \\
\text { change }\end{array}$ & ES \\
\hline CMJ (cm) & $26.32 \pm 8.40$ & $30.76 \pm 9.54$ & $\begin{array}{c}16.87 \pm \\
2.7\end{array}$ & $0.49 \pm 0.02^{\mathrm{b}}$ & $27.66 \pm 5.29$ & $30.82 \pm 6.52+$ & $11.39 \pm 2$ & $0.56 \pm 0.05^{c}$ \\
\hline ABKJ (cm) & $29.43 \pm 9.92$ & $33.39 \pm 10.20$ & $\begin{array}{c}13.45 \pm \\
2.1\end{array}$ & $0.37 \pm 0.02^{b}$ & $31.06 \pm 7.43$ & $33.48 \pm 7.43+$ & $7.80 \pm 1.4$ & $0.31 \pm 0.01^{b}$ \\
\hline $\begin{array}{l}\text { Zig-zag } 10 \mathrm{~m} \\
\text { (s) }\end{array}$ & $6.98 \pm 1.13$ & $6.51 \pm 0.59$ & $6.79 \pm 1.3$ & $0.39 \pm 0.01^{b}$ & $6.94 \pm 0.73$ & $6.90 \pm 0.40$ & $0.52 \pm 0.2$ & $0.04 \pm 0.0^{a}$ \\
\hline \multicolumn{9}{|l|}{ Sprint $20 \mathrm{~m} \mathrm{(s)}$} \\
\hline $0-10 \mathrm{~m}$ & $2.44 \pm 0.27$ & $2.35 \pm 0.21$ & $3.82 \pm 0.8$ & $0.31 \pm 0.02^{\mathrm{b}}$ & $2.38 \pm 0.24$ & $2.27 \pm 0.14 \dagger$ & $4.78 \pm 0.9$ & $0.42 \pm 0.03^{b}$ \\
\hline $10-20 \mathrm{~m}$ & $1.62 \pm 0.12$ & $1.60 \pm 0.16$ & $1.23 \pm 0.4$ & $0.16 \pm 0.01^{\mathrm{a}}$ & $1.62 \pm 0.10$ & $1.59 \pm 0.16$ & $1.85 \pm 0.5$ & $0.30 \pm 0.01^{b}$ \\
\hline $0-20 \mathrm{~m}$ & $3.96 \pm 0.35$ & $3.96 \pm 0.36$ & 0 & 0 & $3.91 \pm 0.38$ & $3.85 \pm 0.29$ & $1.34 \pm 0.4$ & $0.14 \pm 0.0^{\mathrm{a}}$ \\
\hline \multirow[t]{3}{*}{ SRFT (cm) } & $0.71 \pm 1.43$ & $3.64 \pm 1.65+\$$ & $412.6 \pm 40$ & $2.04 \pm 0.24^{\mathrm{e}}$ & $0.56 \pm 1.70$ & $2.94 \pm 1.86+\$$ & $425 \pm 41.3$ & $1.4 \pm 0.17 \mathrm{e}$ \\
\hline & \multicolumn{4}{|c|}{$(n=10)$} & \multicolumn{4}{|c|}{$(n=10)$} \\
\hline & Pre & Post & $\%$ change & ES & Pre & Post & $\begin{array}{c}\% \\
\text { change }\end{array}$ & ES \\
\hline $\mathrm{CMJ}(\mathrm{cm})$ & $27.4 \pm 5.50$ & $28.88 \pm 7.86$ & $5.40 \pm 1.1$ & $0.25 \pm 0.01^{b}$ & $28.01 \pm 4.51$ & $28.14 \pm 4.40$ & $0.46 \pm 0.2$ & $0.02 \pm 0.0^{\mathrm{a}}$ \\
\hline ABKJ (cm) & $31.36 \pm 8.58$ & $33.02 \pm 8.64$ & $5.29 \pm 1$ & $0.18 \pm 0.01^{a}$ & $30.98 \pm 6.30$ & $31.14 \pm 5.15$ & $0.51 \pm 0.2$ & $0.02 \pm 0.0^{\mathrm{a}}$ \\
\hline $\begin{array}{l}\text { Zig-zag } 10 \mathrm{~m} \\
\text { (s) }\end{array}$ & $6.90 \pm 0.63$ & $6.28 \pm 0.58+$ & $9.02 \pm 1.6$ & $0.91 \pm 0.12^{\mathrm{d}}$ & $6.96 \pm 0.64$ & $6.92 \pm 0.63 \#$ & $0.63 \pm 0.2$ & $0.07 \pm 0.0^{\mathrm{a}}$ \\
\hline \multicolumn{9}{|l|}{ Sprint 20 m (s) } \\
\hline $0-10 \mathrm{~m}$ & $2.36 \pm 0.26$ & $2.16 \pm 0.19+$ & $8.49 \pm 1.6$ & $0.71 \pm 0.09 c$ & $2.44 \pm 0.29$ & $2.43 \pm 0.23$ & $0.33 \pm 0.1$ & $0.04 \pm 0.0^{\mathrm{a}}$ \\
\hline $10-20 \mathrm{~m}$ & $1.56 \pm 0.20$ & $1.53 \pm 0.18$ & $1.92 \pm 0.5$ & $0.15 \pm 0.0^{\mathrm{a}}$ & $1.60 \pm 0.15$ & $1.59 \pm 0.22$ & $0.60 \pm 0.2$ & $0.07 \pm 0.01^{\mathrm{a}}$ \\
\hline $0-20 \mathrm{~m}$ & $3.92 \pm 0.45$ & $3.79 \pm 0.38$ & $3.22 \pm 0.8$ & $0.25 \pm 0.01^{b}$ & $4.00 \pm 0.39$ & $3.99 \pm 0.35$ & $0.44 \pm 0.1$ & $0.04 \pm 0.0^{a}$ \\
\hline SRFT (cm) & $0.78 \pm 1.63$ & $2.35 \pm 1.65+$ & $\begin{array}{c}201.2 \pm \\
21.3\end{array}$ & $0.96 \pm 0.13^{\mathrm{d}}$ & $0.63 \pm 1.82$ & $1.27 \pm 1.51 \dagger$ & $101.5 \pm 11$ & $0.34 \pm 0.02^{\mathrm{b}}$ \\
\hline
\end{tabular}

CMJ: counter movement jump; ABKJ: Abalakov jump; SRFT: sit and reach flexibility test; PG: plyometric group; SG: strength group; CODG: change of direction group; CG: control group; S: seconds; M: meters; CM: centimeters; ES: effect size

Values are reported as mean \pm standard deviation.

+ Significant differences (time) between pretraining and posttraining values $(p<.05)$.

$\$$ Significant differences (groups $x$ time) from plyometric group $(P G)$ and strength group $(S G)$ with change of direction group $(C O D G)(p=.025)$.

\# Significant differences (groups $x$ time) from control group (CG) with plyometric group (PG) ( $p=.015$ ), strength group $(S G)(p=.008)$ and change of direction group (CODG) $(p=.001)$. $a, b, c, d$ and e denotes trivial, small, moderate, large and very large $E S$, respectively 


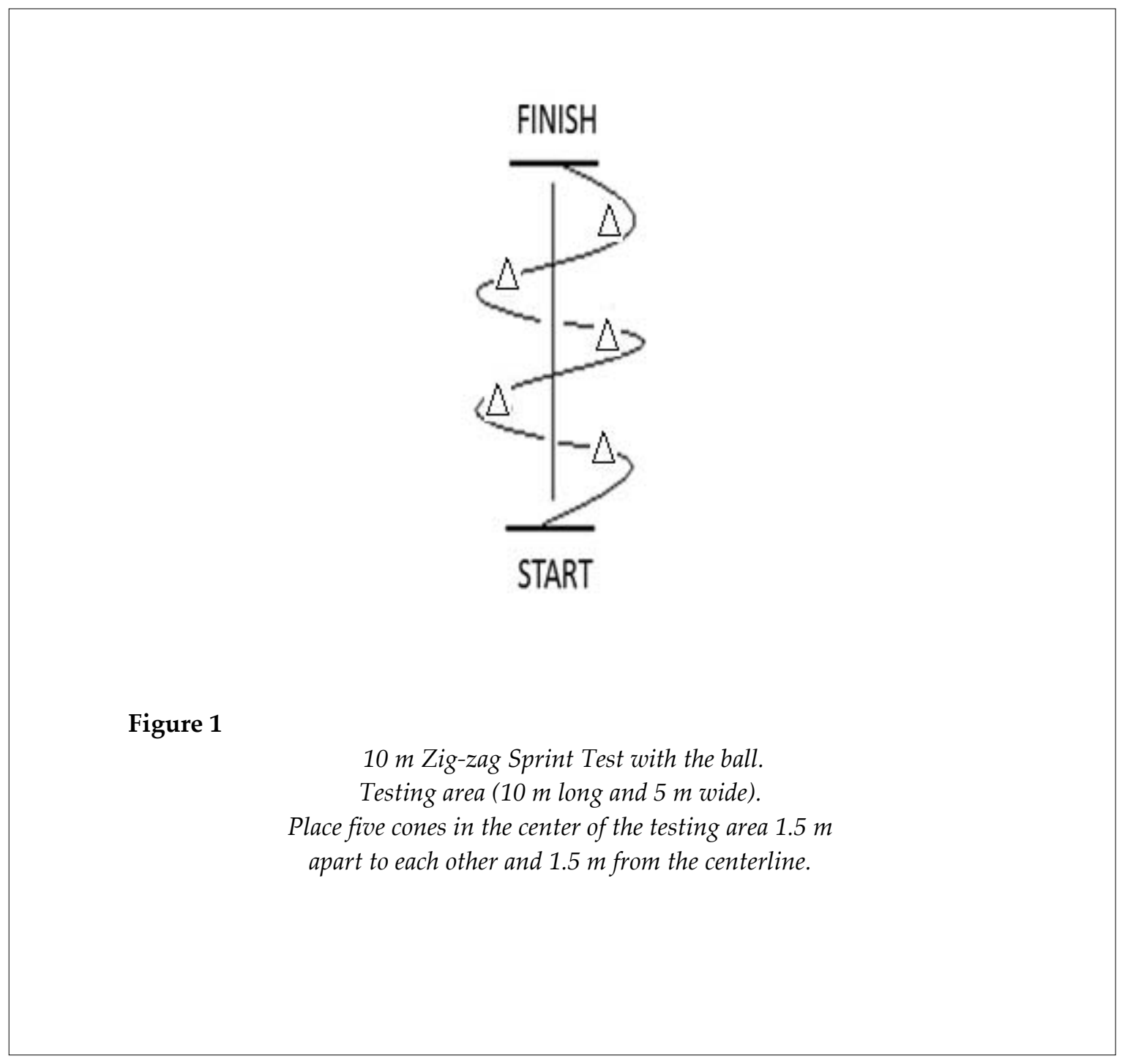

\section{Discussion}

The results of this experiment add knowledge to previous studies on different performance adaptations through the use of traditional strength, plyometric, and COD training with ball approaches in high-school basketball players on a set of basketball-related physical skills, namely jumping, sprinting with a ball and lumbar and hamstring flexibility. Our findings illustrate that a 7 week plyometric training approach results in a greater improvement in vertical jump and COD performance than strength and COD training. The results also show that a COD training program produces a more powerful stimulus in improving COD and sprint performance than the strength training program, and that all the training programs produce a significant improvement in the flexibility conditions.

The PG showed improvements in CMJ and $\mathrm{ABKJ}$ height $(\mathrm{ES}=0.49$ and $\mathrm{ES}=0.37$, respectively). These results are consistent with earlier research (Chappell and Limpisvasti, 2008; Khlifa et al., 2010; Santos and Janeira, 2011; Zribi et al., 2014) in which plyometric training of the lower limbs improved vertical jump performance. Also consistent with previous research (Tansel et al., 2008), we observed improvements in CMJ height $(E S=0.56)$ and ABKJ height $(E S=0.31)$ in the SG. Earlier research found that combined strength and plyometric training had greater effects on vertical jumping than strength training alone (Andrejic, 2012; Santos and Janeira, 2008). The CG also achieved improvements in CMJ 
height $(E S=0.19)$ and in ABKJ height $(E S=0.27)$ due to technical and tactical basketball training. Although the improvements in vertical jumping in the CG were trivial, they nevertheless suggest that technical and tactical basketball training can help to maintain or improve youth basketball players' jumping (Gonzalez et al., 2012). The only group whose jumping performance did not improve was the CODG, which suggests that the COD program used in this study does not improve vertical jumping. This result contrasts with earlier research in which CMJ height improved after 10 weeks of strength training, sprint training, endurance training, and technical and tactical basketball training (Kilinç, 2008). This suggests that combining COD training with strength training, sprint training, endurance training, and technical and tactical basketball training might improve vertical jumping.

Both the SG and CODG showed improvements in time for the first half of the $20 \mathrm{~m}$ sprint $(E S=0.42$ and $E S=0.71$, respectively), but these decreases were not accompanied by improvements in total time for the $20 \mathrm{~m}$ sprint. There were no improvements in the second half of the $20 \mathrm{~m}$ sprint performance; this result is in conflict with other research (Maćkała and Fostiak, 2015; Ramírez-Campillo et al., 2015a, 2015b; Söhnlein et al., 2014) which found that running speed for a $20 \mathrm{~m}$ sprint was improved after a plyometric training program. Ramírez-Campillo et al. (2015b) reported that 6 weeks of plyometric training induced meaningful changes in the $20 \mathrm{~m}$ sprint $(E S=-0.5)$ in 14-y players. The reason of discrepancy in the rate of training effect might be due to different individual adaptive responses to plyometric training (Ramírez-Campillo et al., 2018). It is well known that sprint-running performance is the product of the stride rate and stride length with numerous components influencing this apparently simple task. Since both elements are clearly influenced by anthropometric characteristics, one of the main possible explanation for no improvement in sprint performance could be the anthropometric variable. This is especially important for youth athletes in the early stages of development where the technical abilities still have a great window for improvement. During maturation the natural development of sprint performance occurs due to greater muscle size, increased limb length, changes in musculotendinous tissue, enhanced neural and motor development, and better movement quality and coordination (Oliver and Rumpf, 2014).

Our results are consistent with studies (Monteiro et al., 2008; Ferrete et al., 2014) showing that a stretching program can increase flexibility in young people and adults who have followed a strength training program. All the groups in our study performed passive stretching exercises after their technical and tactical basketball training. It should be noted that all our participants were going through puberty, which may have influenced the results. In descriptive terms the PG, SG, CODG, and CG showed increased flexibility after the 7 week study period. Both the PG and SG showed differences compared with the CODG. These results suggest that it may be worth incorporating stretching exercises into strength training, and technical and tactical basketball training.

Basketball requires athletes to execute complex skills, not only on their preferred side using their dominant hands, but also on their nonpreferred side. Flexible use of the dominant and non-dominant hand is crucial, especially in competitive play, when athletes face pressure from opponents and have to select an appropriate action rapidly (Stöckel et al., 2011). It is relevant to this that only the CODG showed an improvement in performance on the $10 \mathrm{~m}$ zig-zag sprint test (ES $=0.91$ ). The structure of COD training with the ball is much more complex than without the ball. In addition, the basic skills without the ball have much stronger relation among speed, agility, and quickness than the skills with the ball (Sporiš et al., 2011). This may be why the other groups did not show improvement in this test.

Finally, throughout the 7 weeks of training none of the players suffered a lower limb injury during training or match play. Neuromuscular training, resistance training, and plyometric training seem to improve the hamstring-quadriceps neuromuscular properties (Pettitt and Bryson, 2002), thus reducing the risk of injury.

In conclusion, the current study demonstrates that 7 weeks of different training programs (plyometric, strength, and COD) significantly improve vertical jump, sprint, COD, and flexibility performance in high-school 
basketball players. The estimated improvements in the vertical jump, sprint, and COD as a result of plyometric and strength training could be considered as practically relevant and of high importance for athletes in basketball.

Finally, the current study was focused on young male participants. As young males and females clearly experience different effects from plyometric training according to sex specific maturational development, future studies should take a similar approach for female participants. Considering that biological maturity may affect adaptations to strength and conditioning practices

\section{Acknowledgements}

The authors are grateful to the basketball players who participated in this study.

\section{References}

Alemdaroğlu U. The relationship between muscle strength, anaerobic performance, agility, sprint ability and vertical jump performance in professional basketball players. J Hum Kinet, 2012; 31: 149-158

Andrejic $\mathrm{O}$. The effects of a plyometric and strength training program on the fitness performance in young basketball players. FU Phys Ed Sport, 2012; 10(3): 221-229

Asadi A, Arazi H, Young WB, Saez de Villarreal E. The effects of plyometric training on change-of-direction bility: a meta-analysis. Int J Sports Physiol Perform, 2016; 11(5): 563-573. https:// doi: 10.1123/ijspp.20150694

Asadi A, Ramírez-Campillo R, Meylan C, Nakamura FY, Cañas-Jamett R, Izquierdo M. Effects of volumebased overload plyometric training on maximal-intensity exercise adaptations in young basketball players. J Sports Med Phys Fitness, 2017; 57(12): 1557-1563. https://doi.org/10.23736/S00224707.16.06640-8

Banda DS, Beitzel MM, Kammerer JD, Salazar I, Lockie RG. Lower-Body Power Relationships to Linear Speed, Change-of-Direction Speed, and High-Intensity Running Performance in DI Collegiate Women's Basketball Players. J Hum Kinet, 2019; 68: 223-232

Canovas-Lopez M, Arias J, Garcia-Marin P, Yuste JL. Time-motion analysis procedure in team sports: Example for youth basketball. Strength Cond J, 2014; 36(3): 71-75

Chappell JD, Limpisvasti O. Effect of a Neuromuscular Training Program on the Kinetics and Kinematics of Jumping Tasks. Am J Sports Med, 2008; 36(6): 1081-1086. https://doi.org/10.1177/0363546508314425

Delextrat A, Cohen D. Strength, Power, Speed, and Agility of Women Basketball Players According to Playing Position. J Strength Cond Res, 2009; 23(7): 1974-1981. https://doi.org/10.1519/ JSC.0b013e3181b86a7e

Ferrete C, Requena B, Suarez-Arrones L, Saez de Villarreal E. Effect of Strength and High-Intensity Training on Jumping, Sprinting, and Intermittent Endurance Performance in Prepubertal Soccer Players. J Strength Cond Res, 2014; 28(2): 413-422. https://doi.org/10.1519/ JSC.0b013e31829b2222

Gonzalez AM, Hoffman JR, Scallin-Perez JR, Stout JR, Fragala MS. Performance Changes in National Collegiate Athletic Association Division I Women Basketball Players During a Competitive Season. J Strength Cond Res, 2012; 26(12): 3197-3203. https://doi.org/10.1519/ JSC.0b013e318273665d

Gonzalo-Skok O, Tous-Fajardo J, Arjol-Serrano JL, Suarez-Arrones L, Casajús JA, Mendez-Villanueva A. Improvement of Repeated-Sprint Ability and Horizontal-Jumping Performance in Elite Young Basketball Players With Low-Volume Repeated-Maximal-Power Training. Int J Sports Physiol Perform, 2016; 11(4): 464-473. https://doi.org/10.1123/ijspp.2014-0612

Harrison JS. Bodyweight training: A return to basics. Strength Cond J, 2010; 32(2): 52-55

Hedges LV, Olkin I. Statistical methods for meta-analysis. New York: Academic Press; 1985 
Khlifa R, Aouadi R, Hermassi S, Chelly MS, Jlid MC, Hbacha H, Castagna C. Effects of a plyometric training program with and without added load on jumping ability in basketball players. J Strength Cond Res, 2010; 24(11): 2955-2961. https://doi.org/10.1519/JSC.0b013e3181e37fbe

Kilinç F. An intensive combined training program modulates physical, physiological, biomotoric, and technical parameters in women basketball players. J Strength Cond Res, 2008; 22(6): 1769-1778. https://doi.org/10.1519/JSC.0b013e3181854bca

Komi PV. Stretch-shortening cycle: a powerful model to study normal and fatigued muscle. J Biomech, 2000; 33(10): 1197-1206

Komi PV, Bosco C. Utilization of stored elastic energy in leg extensor muscles by men and women. Med Sci Sports, 1978; 10(4): 261-265

Maćkała K, Fostiak M. Acute Effects of Plyometric Intervention-Performance Improvement and Related Changes in Sprinting Gait Variability. J Strength Cond Res, 2015; 29(7): 1956-1965. https://doi.org/10.1519/JSC.0000000000000853

Meylan CM, Cronin JB, Oliver JL, Hopkins WG, Contreras B. The effect of maturation on adaptations to strength training and detraining in 11-15-year-olds. Scan J Med Sci Sports, 2014; 24(3): e156-64. https://doi.org/10.1111/sms.12128

Mirwald RL, Baxter-Jones ADG, Bailey DA, Beunen GP. An assessment of maturity from anthropometric measurements. Med Sci Sports Exerc, 2002; 34(4): 689-694

Monteiro WD, Simão R, Polito MD, Santana CA, Chaves RB, Bezerra E, Fleck SJ. Influence of Strength Training on Adult Women's Flexibility. J Strength Cond Res, 2008; 22(3): 672-677. https://doi.org/10.1519/JSC.0b013e31816a5d45

Moran JJ, Sandercock GRH, Ramírez-Campillo R, Meylan CMP, Collison JA, Parry DA. Age-Related Variation in Male Youth Athletes' Countermovement Jump After Plyometric Training: A MetaAnalysis of Controlled Trials. J Strength Cond Res, 2017a; 31(2): 552-565. https://doi.org/10.1519/JSC.0000000000001444

Moran JJ, Sandercock GRH, Ramírez-Campillo R, Todd O, Collison J, Parry DA. Maturation-Related Effect of Low-Dose Plyometric Training on Performance in Youth Hockey Players. Pediatr Exerc Sci, 2017b; 29(2): 194-202. https://doi.org/10.1123/pes.2016-0151

Moran JJ, Sandercock GRH, Rumpf MC, Parry DA. Variation in Responses to Sprint Training in Male Youth Athletes: A Meta-analysis. Int J Sports Med, 2017c; 38(1): 1-11. https://doi.org/10.1055/s-0042-111439

Oliver JL, Rumpf MC. Speed development in youths. In Strength and conditioning for youth athletes: Science and application. London/New York: Routledge, 80-93; 2014

Pettitt RW, Bryson ER. Training for women's basketball: a biomechanical emphasis for preventing anterior cruciate ligament injury. Strength Cond J, 2002; 24(5): 20-29

Radcliffe JC, Farentinos RC. High-Powered Plyometrics. Champaign, IL: Human Kinetics; 1999

Ramírez-Campillo R, Alvarez C, Gentil P, Moran J, García-Pinillos F, Alonso-Martinez A, Izquierdo M. Interindividual variability in Respopnses to 7 weeks of plyometric jump training in Male youth soccer players. Front Physiol, 2018; 9: 1156

Ramírez-Campillo R, Burgos CH, Henríquez-Olguín C, Andrade DC, Martínez C, Álvarez C, CastroSepúlveda M, Marques MC, Izquierdo, M. Effect of unilateral, bilateral, and combined plyometric training on explosive and endurance performance of young soccer players. J Strength Cond Res, 2015a; 29(5): 1317-1328. https://doi.org/10.1519/JSC.0000000000000762

Ramírez-Campillo R, Meylan C, Álvarez C, Henriquez-Olguín C, Martinez C, Andrade DC, CastroSepúlveda M, Burgos C, Baez EI, Izquierdo, M. The effects of interday rest on adaptation to 6 weeks of plyometric training in young soccer players. J Strength Cond Res, 2015b; 29(4): 972-979. https://doi.org/10.1519/ JSC.0000000000000283

Ramírez-Campillo R, Meylan C, Alvarez C, Henríquez-Olguín C, Martínez C, Cañas-Jamett R, Andrade DC, Izquierdo $\mathrm{M}$. Effects of in-season low-volume high-intensity plyometric training on explosive actions and endurance of young soccer players. J Strength Cond Res, 2014; 28(5): $1335-1342$. https://doi.org/10.1519/JSC.0000000000000284 
Ramírez-Campillo R, Alvarez C, Garcia-Hermoso A, Ramirez-Velez R, Gentil P, Chaabene H, Moran J, Meylan C, Garcia de Alcaraz A, Sanchez-Sanchez J, Nakamura FY, Granacher U, Kraemer W, Izquierdo M. Methodological characteristics and future rirections for plyometric jump training research: A scoping review. Sports Med, 2018; 48(5):1059-1081.

Sáez de Villarreal E, Gonzalez-Badillo JJ, Izquierdo M. Low and moderate plyometric training frequency produce greater jumping and sprinting gains compared with hugh frequency. J Strength Cond Res, 2008; 22: 715-725

Saez de Villarreal E, Kellis E, Kraemer WJ, Izquierdo M. Determining variables of plyometric training for improving vertical jump height performance: A meta-analysis. J Strength Cond Res, 2009; 23: 495-506

Sáez de Villarreal E, Suarez-Arrones L, Requena B, Haff GG, Ferrete C. Effects of Plyometric and Sprint Training on Physical and Technical Skill Performance in Adolescent Soccer Players. J Strength Cond Res, 2015; 29(7): 1894-1903. https://doi.org/10.1519/JSC.0000000000000838

Sanchez-Sanchez J, Carretero M, Ramírez-Campillo R, Petisco C, Diego M, Gonzalo-Skok O, Nakamura FY. Effects of High-intensity training with one versus three changes of direction on youth female basketball players's performance. Kinesiology, 2018; 50, Suppl.1: 117-125

Santos EJ, Janeira MA. Effects of Complex Training on Explosive Strength in Adolescent Male Basketball Players. J Strength Cond Res, 2008; 22(3): 903-909. https://doi.org/10.1519/ JSC.0b013e31816a59f2

Santos EJ, Janeira MA. The effects of plyometric training followed by detraining and reduced training periods on explosive strength in adolescent male basketball players. J Strength Cond Res, 2011; 25(2): 441-452. https://doi.org/10.1519/JSC.0b013e3181b62be3

Santos EJ, Janeira MA. The effects of resistance training on explosive strength indicators in adolescent basketball players. J Strength Cond Res, 2012; 26(10): 2641-2647. https://doi.org/10.1519/ JSC.0b013e31823f8dd4

Slimani M, Chamari K, Miarka B, Del Vecchio FB, Chéour F. Effects of Plyometric Training on Physical Fitness in Team Sport Athletes: A Systematic Review. J Hum Kinet, 2016; 53: 231-247

Söhnlein Q, Müller E, Stöggl TL. The effect of 16-week plyometric training on explosive actions in early to mid-puberty elite soccer players. J Strength Cond Res, 2014; 28(8): 2105-2114. https://doi.org/10.1519/ JSC.0000000000000387

Sporiš G, Milanović Z, Trajković N, Joksimović A. Correlation between speed, agility and quickness (SAQ) in elite young soccer players. Acta Kinesiol, 2011; 5(2): 36-41

Stöckel T, Weigelt M, Krug J. Acquisition of a complex basketball-dribbling task in school children as a function of bilateral practice order. Res Q Exerc Sport, 2011; 82(2): 188-197. https://doi.org/10.1080/ 02701367.2011.10599746

Tansel RB, Salci Y, Yildirim A, Kocak S, Korkusuz F. Effects of eccentric hamstring strength training on lower extremity strength of 10-12 year old male basketball players. Isokinet Exerc Sci, 2008; 16: 81-85

Zribi A, Zouch M, Chaari H, Bouajina E, Ben Nasr H, Zaouali M, Tabka Z. Short-term lower-body plyometric training improves whole body BMC, bone metabolic markers, and physical fitness in early pubertal male basketball players. Pediatr Exerc Sci, 2014; 26(1): 22-32. https://doi.org/10.1123/pes.2013-0053

\section{Corresponding author:}

José Vicente Gutiérrez-Manzanedo, PhD.

Department of Physical Education, University of Cádiz

Avda. República Saharaui s/n, 11519, Puerto Real (Cádiz, Spain)

Phone number: +34 627719754

Fax number: +34 956016253

E-mail address: josegu.manzanedo@uca.es 